\title{
Tissue Performance Characteristics: Closing the Fidelity Gap in Medical Simulations
}

\author{
Jack E Norfleet ${ }^{{ }^{*}}$, Emily Stern ${ }^{2}$ and Yuanli Bai ${ }^{3}$ \\ ${ }^{1}$ Army Research Laboratory, University of Minnesota, Orlando, FL, Minneapolis, USA \\ ${ }^{2}$ Florida State University, Orlando, FL, Minneapolis, USA \\ ${ }^{3}$ University of Central Florida, USA
}

"Corresponding author: Jack E. Norfleet, Army Research Laboratory, University of Minnesota, Orlando, FL, Minneapolis, USA, Tel: 407-384-3897; E-mail: jack.e.norfleet.civ@mail.mil

Rec date: June 20, 2017; Acc date: July 27, 2017; Pub date: July 29, 2017

Copyright: (c) 2017 Norfleet JE, et al. This is an open-access article distributed under the terms of the creative commons attribution license, which permits unrestricted use, distribution, and reproduction in any medium, provided the original author and source are credited.

\begin{abstract}
Medical simulations often lack the fidelity necessary to train higher-level procedures such as surgery. To work around these gaps, organizations with a training mission like the Department of Defense (DoD) often resort to biologic tissues from cadavers and animals.
\end{abstract}

Keywords: Simulation; Training; Education; Pleura; Chest tube; Military; Tension pneumothorax

\section{Introduction}

Medical simulations often lack the fidelity necessary to train higherlevel procedures such as surgery. To work around these gaps, organizations with a training mission like the Department of Defense (DoD) often resort to biologic tissues from cadavers and animals [1]. However, employing biologic tissues introduces significant costs, social issues, and logistical complexity to the training mission. To close this training capability gap, the DoD is leading a multi-institutional effort to improve the fidelity of synthetic and virtual tissues by implementing measured human tissue properties into training simulations.

\section{Problem}

Defining "more realistic" has been a problem plaguing medical simulation for decades. Most synthetic medical simulators use plastics and other polymers that meet availability and price at the cost of fidelity. The fidelity of these materials is validated by the subjective opinions of 'experts'. While acceptable for basic procedural training, the continued use of biological replacements at higher educational levels suggests a fidelity gap.

\section{Research}

To quantify fidelity gaps, the DoD and academia are objectively measuring and describing tissue characteristics and behaviors. The hypothesis they follow is: "simulated tissues based on constitutive models formulated from measured biologic tissue characteristics will behave similar to biologic tissues when subjected to medical interventions." These early studies involve soft tissue mechanics and fracture mechanics.

Large data collections are ongoing at the Universities of Washington and Minnesota where human tissues are tested within 96 hours post mortem, from fresh cadavers younger than 50 years old at the time of death. The age limit is imposed to better understand the tissue properties of the military-aged population. The tissues of interest are identified through detailed cognitive task analyses of the medical procedures taught using simulated and biologic tissues. Concurrently, the Army Research Laboratory and the University of Central Florida are testing simulated tissues from commercial medical training devices.

Donations and synthetics are separated and then cut into dog bone samples in various orientations to detect anisotropy. After preconditioning to reduce viscoelastic effects each sample is subjected to uniaxial tension until fracture. A constitutive stress/stretch curve is plotted and the Ultimate Tensile Strength (UTS) and stretch ratio at fracture $\left(\lambda_{\mathrm{f}}\right)$ are recorded.

\section{Parietal Pleura: A Case Study}

Parietal pleura is the tough, thin membrane that covers the interior of the chest wall. It is critical for training because needle thoracostomy and chest tube placement rely on haptic cues to indicate that the correct space in the body has been accessed [2]. Simulators use various polymer materials to provide this haptic "pop" [3].

In previous work, pleura data from all age groups was compared to synthetics [3]. These data have since been narrowed to a population of 50 years old or younger $(n=48)$ focusing on UTS and $\lambda_{f}$. Significant anisotropy was not detected. One standard deviation above and below the mean $(\overline{\mathrm{x}} \pm \sigma)$ was selected for a $70 \%$ solution. Large $\sigma$ compared to $\overline{\mathrm{x}}$ were experienced due to the natural variance in biologic tissue and the small sample size. The final performance envelopes are UTS $=1.14 \pm$ $0.88 \mathrm{MPa}$ and $\lambda_{\mathrm{f}}=1.76 \pm 0.58$. Representative models were compared.

\section{Results and Discussion}

In Figure 1, a plot of measured human pleura is overlaid on a constitutive model of simulated pleura from a popular medical simulator. It is evident that the performance difference is significant. Hundreds of thousands of soldiers have trained on this simulator model that requires 12 times the force to puncture a pleura that stretches 1.74 times as far as human tissue. 
Citation: Norfleet JE, Stern E, Bai Y (2017) Tissue Performance Characteristics: Closing the Fidelity Gap in Medical Simulations. J Trauma Treat

Page 2 of 2

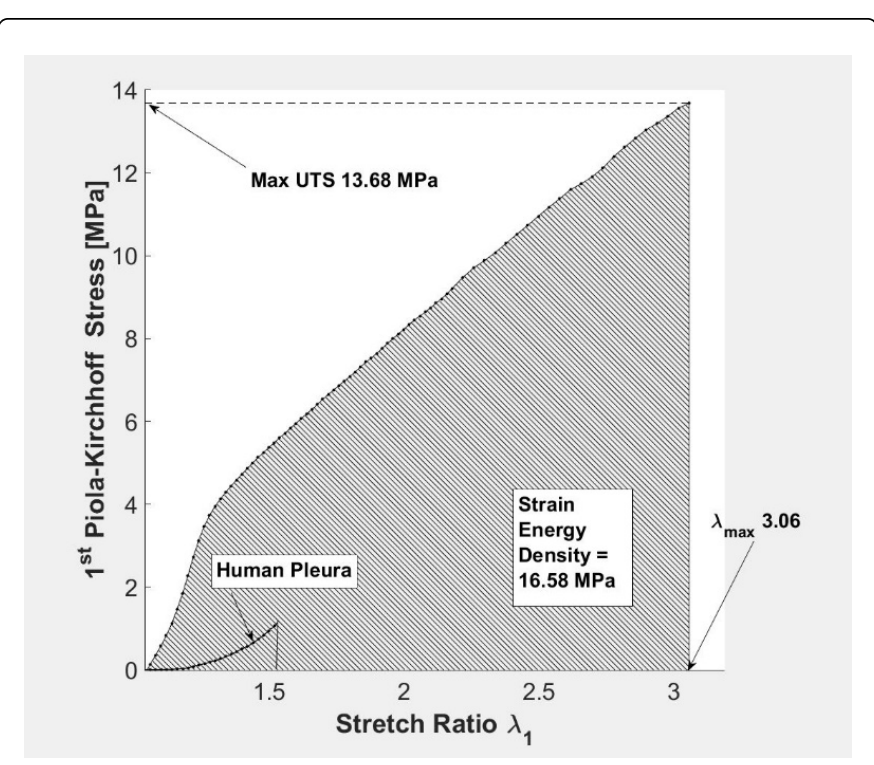

Figure 1: A comparison of constitutive behaviors between human pleura and synthetic pleura.

\section{Conclusion}

Puncturing a tough membrane to blindly enter a small space within the body is a delicate yet violent procedure and the opportunity to introduce negative training effects is great. Prototype pleura are being formulated to meet the measured requirements and further studies will be conducted to assess their effects on learning.

\section{References}

1. Martinic G (2011) The use of animals in live-tissue trauma training and military medical research. Lab Animal 40:319.

2. Lim E, Goldstraw P (2008) Insertion of a chest tube to drain pneumothorax. Anaesth Intensive Care 9: 520-522.

3. Norfleet J, Mazzeo M, Palata K, Tenorio LM, Barocas V, et al. (2016) Thoracostomy Simulations: A comparison of the mechanical properties of human pleura vs synthetic training pleura. MODSIM World. 